\title{
Fibromialgia: aspectos etiopatogênicos e papel do vírus da hepatite $\mathrm{C}$
}

\author{
Sérgio Ricardo Matos Rodrigues da Costa*
}

\begin{abstract}
Resumo
A fibromialgia é uma das síndromes reumatológicas mais comuns. Caracteriza-se especialmente por uma sintomatologia de dor difusa e crônica, geralmente acompanhada de fadiga, e, a um exame físico, de dor à pressão de pontos superficiais específicos ("tender-points"), presentes em número de pelo menos 11 de 18 possíveis. Sua etiopatogenia permanece ainda obscura e mal definida. Há uma grande correlação psicossomática na maior parte dos pacientes, com uma alteração na percepção da dor. Agentes bacterianos e virais podem estar relacionados com a origem da fibromialgia. Desses, o que possui maior correlação com a etiopatogenia dessa síndrome é o vírus da hepatite C. O presente artigo é uma revisão das principais teorias já apresentadas sobre a fibromialgia e das condições mais correlacionadas com a sua origem, com destaque para a possível participação do vírus da hepatite C.
\end{abstract}

Palavras-chave: Fibromialgia. Etiopatogenia. Vírus da hepatite C.

\section{INTRODUÇÃO}

A fibromialgia é uma síndrome não-inflamatória muito comum, que se caracteriza por dor muscular difusa acompanhada de fadiga, associada a dor à pressão de pontos superficiais específicos ("tender-points") e, freqüentemente, a outros sintomas (WOLFE, 1990; ELAM; JOHANSSON; WALLIN, 1992). Há larga aceitação da síndrome de fibromialgia como uma entidade clínica definida, apesar de ser controversa sua designação como uma entidade distinta (WOLFE, 1990; BUCHWALD, 1996), porque a fibromialgia não obedece ao modelo clássico de doença que associa a patologia a agentes etiológicos conhecidos ou a causas predisponentes bem estabelecidas. Esse mesmo modelo não é capaz de favorecer o entendimento de de- sordens somáticas associadas ao psíquico do paciente (WOLFE, 1990).

Segundo o comitê do American College of Rheumatology (1990), a fibromialgia se caracteriza por história de dor difusa e crônica que envolve todos os quatro quadrantes do corpo (e o esqueleto axial) do paciente e pela presença de 11 de 18 "pontos gatilho" ou "tender points" à palpação no exame físico (WOLFE et al., 1990; BUCHWALD, 1996; ALVAREZ; ROCKWELL, 2002)

Os estudos de prevalência da fibromialgia na população mostraram, em diferentes países industrializados, que a freqüência varia de $1 \%$ a $4 \%$ (BUCHWALD, 1996; WOLFE et al., 1997; DEMITRACK, 1998), o que a coloca como a segunda patologia reumatológica mais comum,

\footnotetext{
* Professor de Biofísica

Instituto de Ciências da Saúde. Departamento de Biofunção. UFBA.

Av. Reitor Miguel Calmon s/n Vale do Canela

40.110-100 - Salvador Bahia Brasil

E-mail: srcosta@ufba.br
} 
atrás apenas da osteoartrite. A fibromialgia é mais prevalente em pacientes do sexo feminino. Constata-se nas mulheres aproximadamente nove vezes mais do que nos homens a presença de 11 de 18 "tender-points" (WOLFE et al., 1997).

Embora a etiopatogenia da doença continue obscura, algumas condiçôes estão mais correlacionadas com a sua origem. A fibromialgia freqüentemente ocorre em associação com outras desordens reumáticas ou outros estados dolorosos, sendo constatada em cerca de 25\% dos pacientes com artrite reumatóide (WOLFE; CATHEY; KLEINHEKSEL, 1984), $30 \%$ dos pacientes portadores de lupus eritematoso sistêmico (MIDDLETON; McFARLIN; LIPSKY, 1994) e 50\% de pacientes com síndrome de Sjögren (VITALI et al., 1989). Há também sintomas correlatos, além de alteração da nocicepção periférica, entre pacientes com fibro-mialgia e cistite intersticial, doença esta de etiologia igualmente desconhecida e caracterizada por dor no nível da bexiga e da pelve, acompanhada por urgência urinária e polaciúria (CLAUW et al., 1997).

\section{ETIOPATOGENIA}

Ainda não há uma etiopatogenia bem definida para a fibromialgia, embora se verifique uma grande correlação psicossomática na maior parte dos pacientes (CELIKER et al., 1997; WALKER et al., 1997). Agentes bacterianos e virais podem estar relacionados com a origem dessa patologia, sendo mais forte a correlação entre a doença e a infecção pelo vírus da hepatite C. O Quadro 1 mostra as principais teorias associadas à etiopatogenia da doença.

Pacientes com fibromialgia severa têm redução do limiar de dor (alodinia) e incremento da resposta dolorosa a estímulos (hiperalgesia), além de aumento da duração da dor após estímulo dos nociceptores (KOSEK; EKHOLM; HANSSON, 1996; LAUTHENBACHER; ROLLMAN, 1997). Sugeriu-se que a redução dos níveis de serotonina no sistema nervoso central possa desempenhar algum papel neste fenômeno (RUSSELL, 1989; WOLFE et al.,

\begin{tabular}{|c|c|}
\hline Teoria & Etiopatogenia proposta \\
\hline $\begin{array}{l}\text { Alterações na sensibilidade } \\
\text { dolorosa }\end{array}$ & $\begin{array}{l}\text { Redução dos níveis de } \\
\text { serotonina no sistema } \\
\text { nervoso central } \\
\text { Níveis elevados de } \\
\text { substância P no soro e } \\
\text { líquor } \\
\text { Redução da atividade sérica } \\
\text { da prolil-endopeptidase } \\
\text { Trauma com sensibilização } \\
\text { central }\end{array}$ \\
\hline $\begin{array}{l}\text { Alteraçōes no sistema } \\
\text { nervoso autônomo }\end{array}$ & $\begin{array}{l}\text { Anormalidades em } \\
\text { barorreceptores }\end{array}$ \\
\hline Anormalidades endócrinas & $\begin{array}{l}\text { Redução de GH e } \\
\text { prolactina } \\
\text { Aumento de CRH e ACTH }\end{array}$ \\
\hline Distúrbios psicológicos & $\begin{array}{l}\text { Desregulação central de } \\
\text { mecanismos de resposta à } \\
\text { tensão e ao estresse }\end{array}$ \\
\hline Agentes infecciosos & $\begin{array}{l}\text { Micoplasmas } \\
\text { Vírus da hepatite C }\end{array}$ \\
\hline
\end{tabular}

Quadro 1 - Etiopatogenia da fibromialgia

1997; JUHL, 1998; RUSSELL, 1998; SCHWARZ et al., 1999). A alta prevalência de migrânia em pacientes com fibromialgia, bem como a melhora da sintomatologia de ambas as doenças com o uso de inibidores da monoamina-oxidase combinados ou não com 5-hidroxitriptamina, reforçam a teoria de uma deficiência central de serotonina como desordem comum a essas enfermidades (NICOLODI; SICUTERI, 1996).

Também foram encontrados níveis elevados de substância P no soro (SCHWARZ et al., 1999) e no líquido cefalorraquidiano (RUSELL et al., 1994), além de níveis elevados de homocisteína no líquido cefalorraquidiano (REGLAND et al., 1997) de pacientes com fibromialgia. Foi ainda documentada redução da atividade sérica da prolil-endopeptidase quando pacientes com fibromialgia foram comparados com controles (MAES et al., 1998). Baixas atividades desta peptidase podem estar relacionadas com redução da inativação da dor e com redução da inativação de peptídeos associados à depressão.

Maes e colaboradores (1999) sugeriram que pode haver associação da fibromialgia com anormalidades da resposta inflamatória, alterando a percepção dolorosa, tendo encontrado, em 
pacientes com fibromialgia, valores séricos aumentados de gp130 solúvel, glicoproteína que funciona como transdutor de sinal de várias citocinas neurotróficas. Os autores observaram que os pacientes com maiores escores na escala de depressão, em oposição àqueles com menores escores e a controles sadios, apresentavam valores séricos mais elevados de receptor solúvel de interleucina 6 (sIL-6R) e de antagonista solúvel do receptor de interleucina 1 (sIL-1RA). Smart, Waylonis e Hackshaw (1997) detectaram, em um grupo de 66 pacientes com fibromialgia, a presença de anticorpos antinucleares em 20 deles $(30 \%)$, com $75 \%$ destes apresentando padrão pontilhado, 20\%, padrão difuso e $5 \%$, padrões mistos.

O papel do trauma como desencadeante ou causa de fibromialgia é um assunto importante e contencioso. Pacientes que atribuem a fibromialgia a trauma são mais comprometidos em suas atividades do que aqueles com fibromialgia primária (GREENFIELD; FITZCHARLES; ESDAILE, 1992). Eles apresentam mais inaptidão, dor informada, alteração nas atividades habituais e angústia afetiva. Porém não há qualquer evidência importante de que trauma secundário induza inflamação ou alteração permanentes em músculo ou tecido conjuntivo, que poderiam ser fontes persistentes de estímulos dolorosos.

Um consenso em Vancouver, referente à experiência clínica relativa a trauma e fibromialgia (WINFIELD, 1999), sugeriu que a evidência era "insuficiente para estabelecer relaçôes causais", recomendando que a condição de fibromialgia pós-traumática fosse eliminada. $\mathrm{O}$ argumento a favor de uma conexão entre trauma e fibromialgia está baseado na experiência de certos clínicos e na plausibilidade de sensibilização central como um modelo explicativo para esta associação (WINFIELD, 1999). A adição progressiva de dor e a sensibilização central induziriam, através de estímulos nocivos periféricos, anteriores e contínuos, o resultado de dor persistente na fibromialgia. Pesquisa de dor em animais e certas condições neurológicas humanas identificaram vários mecanismos para sensibilização central, inclusive ativação de ti- pos diferentes de neurônios que respondem a estímulos noci-ceptivos e não nociceptivos, a agentes bio-químicos, como glutamato ou substância P e cito-cinas (CODERRE et al., 1993). Embora teoricamente possível, a idéia de que sensibilização central está por trás da dor em fibromialgia permanece inteiramente especulativa.

Há anormalidades identificáveis na função do sistema nervoso autônomo associadas à fibromialgia. As manifestaçōes clínicas que são relacionadas à deficiência orgânica autonômica não estão completamente claras, mas podem incluir intolerância à ortostase (como em hipotensão neural, por exemplo), instabilidade vasomotora e deficiência orgânica visceral (ELAM; JOHANSSON; WALLIN, 1992).

Há uma relação entre hipotensão de origem neural e fibromialgia. Ambas são desordens associadas especialmente ao sexo feminino. Os sintomas de hipotensão de origem neurológica são semelhantes aos de fibromialgia, inclusive diaforese, visão borrada, náuseas e fadiga (BOU-HOLAIGAH et al., 1997). Uma possibilidade interessante nesta associação é a de que a inibição de barorreceptores arteriais ou algum outro tipo de deficiência orgânica de barorreceptores poderia conduzir a dor aumentada e ansiedade. Esta hipótese origina-se de evidências de que a ativação de barorreceptores arteriais por alteraçôes da pressão sangüínea reduz o limiar de dor, a tolerância à dor e promove ansiedade (ANGRILLI et al., 1997).

Muitos dos sintomas da fibromialgia, inclusive dificuldade de dormir, cansaço, fadiga, mialgias, distúrbios gastrointestinais e diminuição da função cognitiva são semelhantes àqueles observados em indivíduos cujo ritmo circadiano é alinhado anormalmente com o horário de dormir ou com o tempo ambiental local. Embora tenham sido propostas anormalidades em melatonina e cortisol (McCAIN; TILBE, 1989; FERRACCIOLI; CAVALIERI; SALAFFI, 1990; NEECK; CROFFORD, 2000), dois hormônios cujas secreções são influenciadas fortemente pelo ritmo circadiano, Klerman e colaboradores (2001), ao analisar os ritmos circadianos de dez mulheres com fibromialgia e doze mulheres sau- 
dáveis tomadas como controles, não encontraram nenhuma diferença significativa nos ritmos de secreção de melatonina, cortisol e temperatura corporal, sugerindo que anormalidades no ritmo circadiano, no que diz respeito a estes hormônios, não sejam uma causa primária de fibromialgia ou seus sintomas.

Investigações anteriores ao citado trabalho de Klerman e colaboradores (2001) postularam alteraçōes no eixo hipotálamo-hipófise-adrenal em fibromialgia e síndrome da fadiga crônica. Ocorreria hiperatividade do eixo hipotálamohipófise-adrenal em fibromialgia, enquanto a hipofunção do eixo hipotálamo-hipófise-adrenal seria típica em síndrome da fadiga crônica (McCAIN; TILBE, 1989; FERRACCIOLI; CAVALIERI; SALAFFI, 1990; NEECK; CROFFORD, 2000). Quase todos os estudos que investigaram a função do eixo hipotálamohipófise-adrenal em pacientes com fibromialgia descreveram níveis de cortisol elevados associados com um padrão diurno de secreçáo constante (aplainada), como os de McCain e Tilbe (1989) e de Ferraccioli, Cavalieri e Salaffi (1990). Também foram relatados níveis elevados de $\mathrm{CRH}$ e de ACTH em pacientes com a doença (CARROLL et al., 1981; GRIEP; BOERSMA; DE KLOETER, 1993).

Outras doenças também associam freqüentemente hiperatividade do eixo hipototálamohipófise-adrenal com sintomas de depressão. Dois terços de pacientes com síndrome de Cushing apresentam sintomas psiquiátricos que se assemelham à depressão. Pacientes que sofrem de artrite reumatóide extremamente ativa apresentam um padrão de secreção de cortisol, semelhante ao da síndrome de Cushing, que é freqüentemente associado com depressão mental (NEECK et al., 1990). Atividade de CRH aumentada pode ser influenciada adicionalmente através de outros fatores. A serotonina, em particular, parece estar envolvida no estímulo de secreção de ACTH durante tensão (FULLER, 1992).

Embora o local da transformação da dor em sinal no sistema nervoso central não esteja precisamente localizado, considera-se que tensão e sinais de dor alcançam o sistema límbico que exerce atividade inibitória ou de ativação em neurônios produtores de CRH. Parece que as influências de ativação predominam durante tensão e dor. Além de seu efeito clássico aumentando a produção de pró-opiomelanocortina e a secreção de ACTH, CRH funciona como um neurotransmissor para estimular numerosos outros neurônios do sistema nervoso central. Por exemplo, o CRH aumenta a secreção de somatostatina no hipotálamo e em neurônios corticais (WEHRENBERG et al., 1990).

Landis e colaboradores (1997) observaram, durante o período inicial de sono, níveis mais altos de GH e de prolactina em controles do que em pacientes com fibromialgia, com aumentos progressivos durante o sono. Também documentaram uma discreta relação inversa entre latência de sono e prolactina, e uma relação direta entre eficiência de sono e prolactina em fibromialgia, apoiando a hipótese de que sistemas neuroendócrinos desregulados durante o sono podem representar um papel na patofisiologia da fibromialgia, em especial no que diz respeito ao eixo hipotálamo-hipofisário. A idéia de que a fibromialgia era basicamente uma desordem de sono dominou a prática clínica durante um certo tempo (MOLDOFSKY, 1975). Ocorre inversão de ondas do tipo alfa em ritmo REM como uma anomalia de sono distinta em pacientes com esta desordem. Já está claro, porém, que ondas alfa em ritmo REM não são específicas da fibromialgia, pois só uma minoria de pacientes exibe esta anomalia (CARETTE et al., 1995), e a interrupção extrema do sono pode não ser acompanhada por sintomas de fibromialgia. Não obstante, problemas associados ao sono, ou pelo menos a sensação de apresentar alteraçôes no sono, são quase universais em fibromialgia. A queixa freqüente de que uma noite de sono mais pobre é seguida por um dia com mais sintomas de dor tem apoio na pesquisa (AFFLECK et al., 1996).

Outras alterações hormonais foram documentadas em pacientes com fibromialgia, como redução de $\mathrm{GH}$ e de fator do crescimento semelhante à insulina tipo 1 (LEAL-CERRO et al., 1999). A diminuição marcante na secreção espontânea de GH apresenta resposta hipofisária 
normal à administração exógena de GHRH, sugerindo a existência de uma alteração hipotalâmica no controle neuroendócrino da secreção de GH nestes pacientes (LEAL-CERRO et al., 1999).

Várias revisões recentes propuseram que fibromialgia e síndrome da fadiga crônica, juntamente com síndromes de dor crônicas regionais e desordens emocionais, que tão freqüentemente são associadas à fibromialgia, estejam relacionadas com a desregulação central de vários mecanismos de resposta à tensão e ao estresse (CROFFORD; DEMITRACK, 1996). Várias formas de tensão seriam iniciadoras ou perpetuadoras de alterações funcionais (envolvendo hormônio regulador de corticotrofina principalmente) no eixo hipotálamo-hipofisário, no sistema nervoso simpático e, talvez, no metabolismo de serotonina (WINFIELD, 1999), que constituem a base para as manifestações clínicas diversas neste espectro de enfermidade. Possivelmente, mecanismos endócrinos e imunes (por exemplo, interleucinas e outras citocinas) interagem na fisiopatologia da dor, fadiga, depressão, inflamação e de outras alterações que ocorrem na fibromialgia (WINFIELD, 1999). Além de presença, a maior intensidade da dor parece também se associar a distúrbios psicológicos (CELIKER et al., 1997).

Variáveis cognitivas contribuem para a dor em fibromialgia. Convicçôes negativas como ego-culpa para a dor, que a dor é misteriosa, e que vai continuar, são associadas com aumento $\mathrm{da}$ intensidade de dor subjetiva, complacência reduzida com o tratamento, baixa auto-estima, somatização e angústia psicológica (KAROLY; LECCI, 1997; WINFIELD, 1999).

Em outras publicaçôes, a fibromialgia foi usualmente associada a estresse psicológico, vários graus de depressão, ansiedade e crises de pânico (YUNUS, 1994; HUDSON; POPE, 1996; KENNEDY; FELSON, 1996; WALKER et al., 1997; EPSTEIN et al., 1999; WINFIELD, 1999). Cerca de $20 \%$ dos pacientes com fibromialgia apresentam depressão, enquanto cerca de $50 \%$ têm história de depressão durante algum período da vida (HUDSON, 1992; BURCKHARDT et al., 1994).
Freqüentemente, os pacientes relatam muitos problemas relacionados à insatisfação com a qualidade de vida ou o estresse (UVEGES et al., 1990; BURCKHARDT; CLARK; BENETT, 1993). Desordens pessoais graves também foram referidas, como passado de abuso sexual na infância, morte de entes queridos, desilusôes amorosas, problemas financeiros ou ocupacionais/funcionais (PELLEGRINO; WAYLONIS; SOMMER, 1989; TAYLOR; TROTTER; CSUKA, 1995; REID; LANG; MCGRATH, 1997).

\section{AGENTES INFECCIOSOS: VÍRUS DA HEPATITE C}

O papel potencial de infecções na etiopatogenia da fibromialgia e da síndrome da fadiga crônica, em especial as virais, vem sendo recentemente investigado. Buchwald e colaboradores (1996) não encontraram títulos significativos de anticorpos contra 13 tipos de vírus (dentre os quais o vírus da rubéola, o adenovírus, o herpesvírus 6, o vírus de Epstein-Barr, o citomegalovírus, o vírus Cocksakie B) em pacientes com síndrome da fadiga crônica. Alguns vírus que se sugere estariam envolvidos com a síndrome da fadiga crônica não parecem se relacionar com a fibromialgia, como o vírus da doença de Borna (WITTRUP et al., 2000), um RNA-vírus neurotrópico que afeta cavalos e ovelhas, originando anormalidades no comportamento desses animais, e o parvovírus B19 (BERG; NAIDES; SIMMS, 1993).

O micoplasma parece estar envolvido na etiopatogenia da síndrome da fadiga crônica, podendo também estar relacionado com a fibromialgia (NASRALLA, 1999). A espécie mais comumente encontrada em pacientes com síndrome da fadiga crônica e/ou com fibromialgia é o Mycoplasma pneumoniae, seguido do Mycoplasma fermentans, do Mycoplasma hominis e do Mycoplasma penetrans, podendo ocorrer infecções múltiplas por micoplasma (NASRALLA, 1999).

$\mathrm{O}$ agente infeccioso que mais parece estar associado com casos de fibromialgia é o vírus da hepatite $\mathrm{C}$ (VHC). O VHC é um vírus que pos- 
sui RNA infeccioso do tipo mensageiro (SETÚBAL, 1994). É, até o momento, classificado na família Flaviviridae, de acordo com as suas características morfológicas, reaçōes sorológicas e características da glicoproteína $\mathrm{E}$ do envelope lipídico do vírus (associada à aderência viral). Não pertence, entretanto, aos gêneros conhecidos da família Flaviviridae (Flavivirus e Pestivirus) (TAVARES-NETO, 1997), sendo incluído no grupo "flavi-like virus" juntamente com o vírus da hepatite G (LI et al., 1995).

Como todo RNA-vírus, o VHC apresenta, durante o período de replicação, vírions com nucleotídeos de sequêencias variáveis (PARANÁ, 1997), de maneira que há diferenças geográficas entre as variantes virais, podendo originar cepas resistentes, diferentes respostas imunes dos hospedeiros e graus diferentes de sensibilidade e especificidade nos testes sorológicos indicados (PINHO; BASSIT; SÁEZ-ALQUÉZAR, 1995). Os genótipos virais diferem em $31 \%$ a $34 \%$ da seqüência de nucleotídeos, enquanto os subtipos, em 20\% a 23\% (SEEFF; HOOFNAGLE, 2003).
O subtipo viral predominante no Brasil, conforme a classificação de Simmonds e colaboradores (1993) é o 1b, muito embora já tenham sido tipados o 1 a, o 2 a, o 2 b e o 3 a em doadores de sangue e portadores de hepatite crônica (PINHO; BASSIT; SÁEZ-ALQUÉZAR, 1995). O subtipo $1 \mathrm{~b}$ é o que mais se relaciona com a cronicidade da hepatite $\mathrm{C}$, além de provocar hepatite com resposta menos eficiente ao interferon (PINHO et al., 1995). No Quadro 2, encontram-se algumas características dos principais subtipos conhecidos do vírus da hepatite C (BONKOVSKY; MEHTA, 2001).

Estima-se que cerca de 170 milhôes de pessoas estariam infectadas com o vírus da hepatite C, perfazendo quase $3 \%$ da população mundial (BONKOVSKY; MEHTA, 2001; MARSANO, 2003; SEEFF; HOOFNAGLE, 2003). Em naçôes desenvolvidas, a prevalência da taxa de anticorpos ao VHC geralmente é menor do que 3\%, e entre doadores de sangue voluntários é menor do que 1\% (BONKOVSKY; MEHTA, 2001).

Prevalência nos Estados Unidos (\% pacientes)

\begin{tabular}{|l|l|l} 
Genótipo/Subtipo & $\%$ & Observaçōes \\
\hline
\end{tabular}

$1 \mathrm{a}$

$1 b$

$1 \mathrm{c}$

$2 \mathrm{a} / \mathrm{b} / \mathrm{c}$

$3 a / b \quad-4-6$

$4<5$

$5<5$

$6<5$
Difícil de erradicar com as terapias atualmente disponíveis

$$
-15-20
$$

Difícil de erradicar com as terapias atualmente disponíveis; maior prevalência na Europa, Turquia, no Japão, em Taiwan

Difícil de erradicar com as terapias atualmente disponíveis

Amplamente distribuído; responde melhor às terapias atualmente disponíveis

Encontrado principalmente na Índia, Austrália, Escócia, no Paquistão

Encontrado principalmente na África Centro-Oriental

Encontrado principalmente na África do Sul

Encontrado principalmente em Hong Kong e Macau

Quadro 2 - Genótipos e subtipos de vírus da hepatite C 
A transmissão do VHC ocorre com maior freqüência através de transfusōes sangüíneas ou de hemoderivados (TAVARES-NETO, 1997), bem como por via parenteral não-transfusional e percutânea em toxicômanos, pacientes expostos a métodos diagnósticos invasivos, feitura de tatuagens, hemodiálise, transplantes, e em profissionais da área de saúde. Práticas tradicionais, como acupuntura com agulhas não esterilizadas, e acidentes ocasionais, como lesôes incisas com facas não esterilizadas, foram identificadas como modos prováveis de transmissão (BONKOVSKY; MEHTA, 2001). O uso constante de cocaína intranasal é um outro fator de risco (MARSANO, 2003). Existe também associação com relações sexuais e promiscuidade (MARTINS et al., 1995). Profissionais de saúde apresentam uma prevalência de infecção por VHC três a quatro vezes maior do que a população em geral (MARSANO, 2003).

A freqüência de anticorpos anti-VHC em candidatos à doação de sangue no Brasil já variou de $0 \%$ a $8,2 \%$ (VANDERBORGHT et al., 1995; CARRILHO; SILVA, 1995), constatando-se as frequiências mais elevadas (2,7\% a 8,2\%) no Estado do Amazonas (CARRILHO; SILVA, 1995).

Complicações reumatológicas em infecção por VHC são comuns, incluindo crioglobulinemia mista, vasculites, sintomas comuns à síndrome de Sjögren (cerato-conjuntivite "sicca", com envolvimento de glândulas lacrimais, e xerostomia, com envolvimento de glândulas salivares, porém sem a presença de antígenos virais nestas glândulas), mialgias, artrite e fibromialgia (MEHTA; LEVEY; BONKOVSKY, 1998; BUSKILA, 2000; OLIVIERI; PALAZZI; PADULA, 2003). A presença de artrite associada a crioglobulinemia em infecções por VHC se caracteriza por um quadro intermitente mono- ou oligoarticular, sem erosões ou deformidades, afetando principalmente grandes e médias articulaçôes (BUSKILA, 2000). Além disso, pacientes infectados por VHC apresentam alta prevalência de auto-anticorpos, usualmente em baixos títulos (BUSKILA et al., 1998; BUSKILA, 2000). A hepatite C pode apresentar manifestaçôes reumáticas indistinguíveis da artrite reumatóide, com tenossinovite palmar e sinovite de pequenas articulaçôes (LOVY; STARKEBAUM; UBEROI, 1996).

O estímulo para a produção de determinadas citocinas pelo sistema imunológico dos indivíduos infectados pelo VHC teria um papel na origem de alguns sintomas correlacionados com esta infecção. Algumas citocinas, como as interleucinas 1 e 6 e o fator de necrose tumoral alfa, são elevadas em alguns pacientes infectados pelo VHC (GERSHON et al., 2000). Estas citocinas teriam ação no sistema nervoso central, promovendo sintomas como a fadiga, que pode ocorrer em casos de infecção pelo VHC (GERSHON et al., 2000). Talvez este também seja o mecanismo para desenvolvimento de fibromialgia nos casos em que ocorra a infecção pelo VHC.

Buskila e colaboradores (1997) encontraram alta prevalência de fibromialgia em pacientes infectados com vírus da hepatite C, especialmente mulheres. Nessa casuística, 14 (16\%) de 90 pacientes positivos para o VHC apresentavam fibromialgia, sendo 13 do sexo feminino.

Goulding (2001) avaliou 77 pacientes com VHC e observou que quatro (5\%) dos pacientes cumpriam o critério diagnóstico para fibromialgia, sendo que três eram positivos ao PCR. Também estavam aumentados a ansiedade e os níveis de depressão em pacientes de VHC quando comparados com controles.

Anteriormente, Rivera e colaboradores (1997) determinaram a prevalência de infecção por VHC em 112 pacientes com fibromialgia, em comparação com o mesmo número de pacientes com artrite reumatóide tomados como controles. Anticorpos anti-VHC foram observados, através de ELISA, em 17 pacientes com fibromialgia $(15,2 \%)$ em oposição a seis controles com artrite reumatóide (5,3\%). O exame de RIBA para VHC foi positivo em 16 destes pacientes com fibromialgia, sendo indeterminado em apenas um caso, enquanto o VHCRNA sérico foi observado em 13 destes pacientes. Os autores também observaram a prevalência de fibromialgia em 58 pacientes com hepatite crônica por VHC quando comparados com o grupo controle constituído de pacientes de 
clínica cirúrgica. Foi constatada dor muscular difusa em 31 pacientes com hepatite crônica por VHC (53\%), e a fibromialgia foi diagnosticada em seis (10\%). No grupo controle, 13 apresentaram dor muscular difusa (22\%), e em apenas uma paciente $(1,7 \%)$ diagnosticou-se a fibromialgia. Estes dados sugerem uma possível associação entre VHC e fibromialgia. Esta associação ainda precisa ser melhor investigada para que se determine a contribuição do vírus da hepatite $\mathrm{C}$ na prevalência de fibromialgia.

\title{
Fibromyalgia: etiopathogenic aspects and the role of the hepatitis $C$ virus
}

\begin{abstract}
Fibromyalgia is one of the most common rheumatologic syndromes. It is specially characterized by a symptomatology of a diffuse and chronic pain, generally followed by fatigue; as far as the physical exam is concerned, it is followed by pain when specific superficial points (11 to 18) are pressed ("tender-points"). Its etiopathogeny is still obscure and has not been well defined. There is a great psychosomatic correlation in most patients: alterations in the pain perception. Bacterial and viral agents may be related with the origin of that pathology. The hepatitis $C$ virus is notably the one that presents greater correlation with the etiopathogeny of the fibromyalgia. The present paper reviews the main fibromyalgia theories and the most frequent conditions related to its origin, emphasizing the possible participation of the hepatitis $C$ virus.
\end{abstract}

Keywords: Fibromyalgia. Etiopathogeny. Hepatitis C virus.

\section{REFERÊNCIAS}

AFFLECK, G. et al. Sequential daily relations of sleep, pain intensity, and attention to pain among women with fibromyalgia. Pain, Amsterdam, n.68, p.363-368, 1996.

ALVAREZ, D. J.; ROCKWELL, P. G. Trigger points: diagnosis and management. Am. Fam. Physician, Kansas City, v.65, n.4, p.653-660, 2002.

ANGRILLI, A. et al. The influence of low blood pressure and baroreceptor activity on pain responses. Physiol. Behav., New York, v.62, n.2, p.391-397, 1997.

BERG, A.M.; NAIDES, S. J.; SIMMS, R. W. Established fibromyalgia syndrome and parvovirus B19 infection. J. Rheumatol., Toronto, v.20, p.1941-1943, 1993.

BONKOVSKY, H.L.; MEHTA, S. Hepatitis C: a review and update. J. Am. Acad. Dermatol., St. Louis, v.44, n.2, p.159-182, 2001.

BOU-HOLAIGAH, I. et al. Provocation of hypotension and pain during upright tilt table testing in adults with fibromyalgia. Clin. Exp. Rheumatol., Pisa, v.15, n.3, p.239-246, 1997.
BUCHWALD, D. Fibromyalgia and chronic fatigue syndrome. Rheum. Dis. Clin. North Am., Philadelphia, v.22, n.2, p.219-243, 1996.

BUCHWALD, D. et al. Viral serologies in patients with chronic fatigue and chronic fatigue syndrome. J. Med. Virol., New York, v.50, n.1, p.25-30, 1996.

BURCKHARDT, C. S. et al. Assessing depression in fibromyalgia patients. Arthritis Care Res., Hagerstown, n.7, p.35-39, 1994.

BURCKHARDT, C. S.; CLARK, S. R.; BENNETT, R. M. Fibromyalgia and quality of life: a comparative analysis. J. Rheumatol., Toronto, v.20, p.475-479, 1993.

BUSKILA, D. Hepatitis C-associated arthritis. Curr. Opin. Rheumatol., London, v.12, n.4, p.295-299, 2000.

BUSKILA, D.; NEUMANN, L. Fibromyalgia syndrome (FM) and nonarticular tenderness in relatives of patients with FM. J. Rheumatol., Toronto, v.24, n.5, p.941944, 1997. 
BUSKILA, D. et al. Fibromyalgia in hepatitis $\mathrm{C}$ virus infection: another infectious disease relationship. Arch. Intern. Med., Chicago, v.157, n.21, p.2497-2500, 1997.

BUSKILA, D. et al. Musculoskeletal manifestations and autoantibody profile in 90 hepatitis $\mathrm{C}$ virus infected Israeli patients. Semin. Arthritis Rheum., Philadelphia, v.28, n.2, p.107-113, 1998.

CARETTE, S. et al. Sleep electroencephalography and the clinical response to amitriptyline in patients with fibromyalgia. Arthritis Rheum., New York, v.38, n.9, p.1211-1217, 1995.

CARRILHO, F. J.; SILVA, L. C. Epidemiologia das hepatites virais. In: SILVA, L. C. (Ed.). Hepatites agudas e crônicas. 2.ed. São Paulo: Sarvier, 1995. p.73-95.

CARROLL, B. J. et al. A specific laboratory test for the diagnosis of melancholia. Arch. Gen. Psychiatry, Chicago, v.38, n.1, p.15-22, 1981.

CELIKER, R. et al. Psychological disturbance in fibromyalgia: relation to pain severity. Clin. Rheumatol., Brussels, v.16, n.2, p.179-184, 1997.

CLAUW, D. J. et al. The relationship between fibromyalgia and interstitial cystitis. J. Psychiatr. Res., Oxford, v.31, n.1, p.125-131, 1997.

CODERRE, T. J. et al. Contribution of central neuroplasticity to pathological pain: review of clinical and experimental evidence. Pain, Amsterdam, v.52, n.3, p.259-285, 1993.

CROFFORD, L.J. et al. Hypothalamic-pituitary-adrenal axis perturbations in patients with fibromyalgia. Arthritis Rheum., New York, v.37, n.11, p.1583-1592, 1994.

CROFFORD, L. J.; DEMITRACK, M. A. Evidence that abnormalities of central neurohormonal systems are key to understanding fibromyalgia and chronic fatigue syndrome. Rheum. Dis. Clin. North Am., Philadelphia, v.22, n.2, p.267-284, 1996.

DEMITRACK, M. A. Chronic fatigue syndrome and fibromyalgia: dilemmas in diagnosis and clinical management. Psychiatr. Clin. North Am., Philadelphia, v.21, n.3, p.671-692, 1998.

ELAM, M.; JOHANSSON, G.; WALLIN, B. G. Do patients with primary fibromyalgia have an altered muscle sympathetic nerve activity? Pain, Amsterdam, v.48, n.73, p.371-375, 1992.

EPSTEIN, A. S. et al. Psychiatric disorders in patients with fibromyalgia: a multicenter investigation. Psychosomatics, Washington, DC, v.40, n.1, p.57-63, 1999.
FERRACCIOLI, G.; CAVALIERI, G.; SALAFFI, F. Neuroendocrinologic findings in primary fibromyalgia and in other rheumatic conditions. J. Rheumatol., Toronto, v.17, p.869-877, 1990.

FULLER, R. W. The involvement of serotonin in regulation of pituitary-adrenocortical function. Front. Neuroendocrinol., Orlando, n.13, p.250-258, 1992.

GHERSON, A. S. et al. Serum cytokine values and fatigue in chronic hepatitis C infection. J. Viral Hepat., Oxford, v.7, p.397-402, 2000.

GOULDING, C. Prevalence of fibromyalgia, anxiety and depression in chronic hepatitis $\mathrm{C}$ virus infection: relationship to RT-PCR status and mode of acquisition. Eur. J. Gastroenterol. Hepatol., Melbourne, v.13, n.5, p.507-511, 2001.

GREENFIELD, S.; FITZCHARLES, M.A.; ESDAILE, J.M. Reactive fibromyalgia syndrome. Arthritis Rheum., New York, v.35, n.6, p.678-681, 1992.

GRIEP, E. N.; BOERSMA, J. W.; De KLOET, E. R. Altered reactivity of the hypothalamic-pituitary-adrenal axis in the primary fibromyalgia syndrome. J. Rheumatol., Toronto, v.20, n.3, p.469-474, 1993.

HUDSON, J. I.; POPE JR., H. G. The relationship between fibromyalgia and major depressive disorder. Rheum. Dis. Clin. North Am., Philadelphia, v.22, n.2, p.285-303, 1996.

HUDSON, J. I. et al. Comorbidity of fibromyalgia with medical and psychiatric disorders. Am. J. Med., New York, v.92, p.363-367, 1992.

JUHL, J. H. Fibromyalgia and the serotonin pathway. Altern. Med. Rev., Sandpoint, v.3, n.5, p.367-375, 1998.

KAROLY, P.; LECCI, L. Motivational correlates of selfreported persistent pain in young adults. Clin. J. Pain, Hagerstown, v.13, n.2, p.104-109, 1997.

KENNEDY, M.; FELSON, D. T. A prospective longterm study of fibromyalgia syndrome. Arthritis Rheum., New York, v.39, n.4, p.682-685, 1996.

KLERMAN, E. B. et al. Circadian rhythms of women with fibromyalgia. J. Clin. Endocrinol. Metab., Bethesda, v.86, n.3, p.1034-1039, 2001.

KOSEK, E.; EKHOLM, J.; HANSSON, P. Sensory dysfunction in fibromyalgia patients with implications for pathogenic mechanisms. Pain, Amsterdam, v.68, n.23, p.375-383, 1996.

LANDIS, C. A. et al. Decreased nocturnal levels of prolactin and growth hormone in women with fibromyalgia. J. Clin. Endocrinol. Metab., Bethesda, v.86, n.4, p.1672-1678, 2001 
LAUTENBACHER, S.; ROLLMAN, G. B. Possible deficiencies of pain modulation in fibromyalgia. Clin. J. Pain, Hagerstown, v.13, n.3, p.189-196, 1997.

LEAL-CERRO, A. et al. The growth hormone (GH)releasing hormone-GH-insulin-like growth factor-1 axis in patients with fibromyalgia syndrome. J. Clin. Endocrinol. Metab., Bethesda, v.84, n.9, p.3378-3381, 1999.

LI, X. et al. Identification of hepatitis $\mathrm{C}$ virus by immunoelectron microscopy. J. Viral Hepat., Oxford, v.2, p.227-234, 1995.

LOVY, M. R.; STARKEBAUM, G.; UBEROI, $S$. Hepatitis $C$ infection presenting with reumatic manifestations: a mimic of rheumatoid arthritis. J. Rheumatol., Toronto, v.23, n.6, p.979-983, 1996.

MAES, M. et al. The immune-inflammatory pathophysiology of fibromyalgia: increased serum soluble gp130, the common signal transducer protein of various neurotrophic cytokines. Psychoneuroendocrinology, Oxford, v.24, n.4, p.371-383, 1999.

MAES, M. et al. Lower serum activity of prolyl endopeptidase in fibromyalgia is related to severity of depressive symptoms and pressure hyperalgesia. Psychol. Med., London, v.28, n.4, p.957-965, 1998.

MARSANO, L. S. Hepatitis. Prim. Care, Philadelphia, v.30, n.1, p.81-97, 2003.

MARTINS, R. M. B. et al. Prevalence of hepatitis C viral antibody among Brazilian children, adolescents and street youths. Am. J. Trop. Med. Hyg., McLean, v.53, p.654655, 1995.

McCAIN, G. A. A cost effective approach to the diagnosis and treatment of fibromyalgia. Rheum. Dis. Clin. North Am., Philadelphia, v.22, n.2, p.323-349, 1996.

McCAIN, G. A.; TILBE, K. S. Diurnal hormone variation in fibromyalgia syndrome: a comparison with rheumatoid arthritis. J. Rheumatol., Toronto, v.16, p.154-159, 1989.

MEHTA, S.; LEVEY, J. M.; BONKOVSKY, H. L. Extrahepatic manifestations of infection with hepatitis $\mathrm{C}$ virus. Clin. Liver Dis., Philadelphia, v.5, n.4, 1998.

MIDDLETON, G. D.; McFARLIN, J. E.; LIPSKY, P. E. The prevalence and clinical impact of fibromyalgia in systemic lupus erythematosus. Arthritis Rheum., New York, v.37, n.8, p.1181-1188, 1994.

MOLDOFSKY, H. et al. Musculoskeletal symptoms and non-REM sleep disturbance in patients with "fibrositis syndrome" and healthy subjects. Psychosom. Med., Hagerstown, v.37, n.4, p.341-351, 1975.
NASRALLA, M. Multiple mycoplasmal infections detected in blood of patients with chronic fatigue syndrome and/or fibromyalgia syndrome. Eur. J. Clin. Microbiol. Infect. Dis., Berlin, v.18, n.12, p.859-865, 1999.

NEECK, G. et al. Adrenal secretion of cortisol in patients with rheumatoid arthritis. J. Rheumatol., Toronto, v.17, n.1, p.24-29, 1990.

NEECK, G.; CROFFORD, L. J. Neuroendocrine perturbations in fibromyalgia and chronic fatigue syndrome. Rheum. Dis. Clin. North Am., Philadelphia, v.26, n.4, p.989-1002, 2000.

NICOLODI, M.; SICUTERI, F. Fibromyalgia and migraine, two faces of the same mechanism: serotonin as the common clue for pathogenesis and therapy. Adv. Exp. Med. Biol., New York, v.398, p.373-379, 1996.

OLIVIERI, I.; PALAZZI, C.; PADULA, A. Hepatitis C virus and arthritis. Rheum. Dis. Clin. North Am., Philadelphia, v.29, n.1, p.111, 2003.

PARANÁ, R. Estudo clínico sorológico da hepatite aguda não-A não-B em Salvador-Bahia. 1997. Tese (Doutorado) - Faculdade de Medicina, Universidade Federal da Bahia, Salvador, 1997.

PELLEGRINO, M.J.; WAYLONIS, G. W.; SOMMER, A. Familial occurrence of primary fibromyalgia. Arch. Phys. Med. Rehabil., Philadelphia, v.70, n.1, p.61-65, 1989.

PINHO, J. R. R.; BASSIT, L.; SÁEZ-ALQUÉZAR, A. Estrutura dos vírus das hepatites. In: SILVA, L. C. (Ed.). Hepatites agudas e crônicas. 2.ed. São Paulo: Sarvier, 1995. p.9-25.

REGLAND, B. et al. Increased concentrations of homocysteine in the cerebrospinal fluid in patients with fibromyalgia and chronic fatigue syndrome. Scand. J. Rheumatol., Stockholm, v.26, n.4, p.301-307, 1997.

REID, G. J.; LANG, B. A.; MCGRATH, P. J. Primary juvenile fibromyalgia: psychological adjustment, family functioning, coping, and functional disability. Arthritis Rheum., New York, v.40, n.4, p.752-760, 1997.

RIVERA, J. et al. Fibromyalgia-associated hepatitis C virus infection. Br. J. Rheumatol., Oxford, v.36, n.9, p.981-985, 1997.

RUSSELL, I. J. Advances in fibromyalgia: possible role for central neurochemicals. Am. J. Med. Sci., Hagerstown, v.315, n.6, p.377-384, 1998.

RUSSELL, I.J. Neurohormonal aspects of fibromyalgia syndrome. Rheum. Dis. Clin. North Am., Philadelphia, v.15, p.149-168, 1989. 
RUSSELL, I. J. et al. Elevated cerebrospinal fluid levels of substance $P$ in patients with the fibromyalgia syndrome. Arthritis Rheum., New York, v.37, p.1593-1601, 1994.

SCHWARZ, M. J. et al. Relationship of substance P, 5hydroxyindole acetic acid and tryptophan in serum of fibromyalgia patients. Neurosci. Lett., Limerick, v.259, n.3, p.196-198, 1999.

SEEFF, L. B.; HOOFNAGLE, J. H. Appendix: The National Institutes of Health Consensus Development Conference: Management of Hepatitis C 2002. Clin. Liver Dis., Philadelphia, v.7, n.1, p.261-279, 2003.

SETÚBAL, S. Flaviviridae. In: OLIVEIRA, L. H. S. (Ed.). Virologia humana. Rio de Janeiro: Cultura Médica, 1994. p.94-109.

SIMMONDS, P. et al. Sequence variability in the 5' non-coding region of hepatitis $C$ virus type and restriction on sequence diversity. J. Gen. Virol., London, v.74, p.661-668, 1993.

SMART, P. A.; WAYLONIS, G. W.; HACKSHAW, K.V. Immunologic profile of patients with fibromyalgia. Am. J. Phys. Med. Rehabil., Hagerstown, v.76, n.3, p.231234, 1997.

TAVARES-NETO, J. Marcadores sorológicos das hepatites B e C em residentes de área endêmica da esquistossomose mansônica. 1997. Tese (LivreDocência) - Faculdade de Medicina, Universidade Federal da Bahia, Salvador, 1997.

TAYLOR, M. L.; TROTTER, D. R.; CSUKA, M. E. The prevalence of sexual abuse in women with fibromyalgia. Arthritis Rheum., New York, v.38, p.229234, 1995.

UVEGES, J. M. et al. Psychological symptons in primary fibromyalgia syndrome: relationship to pain, life stress, and sleep disturbance. Arthritis Rheum., New York, v.33, p.1279-1283, 1990.

VANDERBORGHT, B. O. M. et al. High prevalence of hepatitis $\mathrm{C}$ infection among Brazilian hemodialysis patients in Rio de Janeiro: a one-year follow-up study. R. Inst. Med. Trop. São Paulo, São Paulo, n.37, p.75-79, 1995.
VITALI, C. et al. Fibromyalgia features in patients with primary Sjögren syndrome: evidence of a relationship with psycological depression. Scand. J. Rheumatol., Stockholm, v.18, p.21-27, 1989.

WALKER, E. A. et al. Psychosocial factors in fibromyalgia compared with rheumatoid arthritis: I. Psychiatric diagnoses and functional disability. Psychosom. Med., Hagerstown, v.59, n.6, p.565-571, 1997.

WALKER, E. A. et al. Psychosocial factors in fibromyalgia compared with rheumatoid arthritis: II. Sexual, physical, and emotional abuse and neglect. Psychosom. Med., Hagerstown, v.59, n.6, p.572-577, 1997.

WEHRENBERG, W. B. et al. Glucocorticoids: potent inhibitors and stimulators of growth hormone secretion. Endocrinology, Baltimore, v.126, n.6, p.3200-3203, 1990.

WINFIELD, J. B. Pain in fibromyalgia. Rheum. Dis. Clin. North Am., Philadelphia, v.25, n.1, p.55-79, 1999.

WITTRUP, I. H. et al. Search for Borna disease virus in Danish fibromyalgia patients. Scand. J. Rheumatol., Stockholm, v.29, n.6, p.387-390, 2000.

WOLFE, F. The relation between tender points and fibromyalgia symptom variables: evidence that fibromyalgia is not a discrete disorder in the clinic. Ann. Rheum. Dis., London, v.56, n.4, p.268-271, 1997.

WOLFE, F.; CATHEY, M. A.; KLEINHEKSEL, S. M. Fibrositis (fibromyalgia) in rheumatoid arthritis. J. Rheumatol., Toronto, v.11, p.814-818, 1984.

WOLFE, F. et al. The American College of Rheumatology 1990 criteria for the classification of fibromyalgia: Report of the Multicenter Criteria Committee. Arthritis Rheum, New York, v.33, p.160-172, 1990.

WOLFE, F. et al. Serotonin levels, pain threshold, and fibromyalgia symptoms in the general population. J. Rheumatol., Toronto, v.24, n.3, p.555-559, 1997.

YUNUS, M. B. Psychological aspects of fibromyalgia syndrome: a component of the dysfunctional spectrum syndrome. Baillieres Clin. Rheumatol., London, v.8, p.811-837, 1994.

\section{Agradecimento}

Ao Professor José Tavares-Neto, pela importante orientação. 